\title{
STRATEGI DALAM MELAKUKAN TERMINASI PADA KEKERASAN SEKSUAL ANAK DI LRSAMPK DARUSSA'ADAH
}

\author{
Rika Dewi Auliani Usman dan Nurul Husna \\ UIN Ar-Raniry Banda Aceh \\ Email: rika.dewiauliani@yahoo.co.id
}

\begin{abstract}
Sexual crimes occur not only in urban areas but also in villages. This crime has a big impact especially the majority of victims are children. LRSAMPK Darussa'adah is an institution whose role is to provide services for victims. The purpose of this study was to determine the types of cases of child sexual violence, the strategies carried out by the assistants in terminating and barriers, challenges and support in terminating. This is a field research with a qualitative approach. Data collection techniques are observation, interviews and documentation, then the research results are analyzed descriptively. The results showed that the types of child sexual abuse cases handled by LRSAMPK Darussa'adah were rape, sexual harassment, sexual exploitation, neglect of the baby, sexual abuse and abduction for sexual purposes. The accompanying strategy in terminating child sexual abuse cases is to convince the victims' families and communities by involving referrals, "geuchik", social workers and related agencies. The challenges of Darussa'adah social workers are when client stakeholders are difficult to ask for information about victims and there are some people who refuse and some accept victims. The support received by Darussa'adah social workers is when the referrals are willing to work together to find ways to facilitate the termination of victims, and also families and there are still people who are willing to accept among the majority of people who refuse victims returning,
\end{abstract}

Keywords: Sexual Violence, Case Assistance, Termination.

Abstrak. Kejahatan seksual marak terjadi tidak hanya di perkotaan tetapi meluas ke perkampungan. Kejahatan ini berdampak besar khususnya sebagian besar korbannya adalah anak-anak. LRSAMPK Darussa'adah merupakan lembaga yang berperan memberi pelayanan bagi korban. Tujuan penelitian ini adalah mengetahui jenis kasus kekerasan seksual anak, strategi yang dilakukan oleh pendamping dalam melakukan terminasi dan hambatan, tantangan maupun dukungan dalam melakukan terminasi. Ini adalah penelitian lapangan (field research) dengan pendekatan kualitatif. Teknik pengumpulan data adalah observasi, wawancara dan dokumentasi, selanjutnya hasil penelitian dianalisis secara deskriptif. Hasil penelitian menunjukkan bahwa jenis kasus kekerasan seksual anak yang ditangani LRSAMPK Darussa'adah adalah perkosaan, pelecehan seksual, eksploitasi seksual, penelantaran bayi, pencabulan perdagangan dan penculikan untuk tujuan seksual. Strategi pendamping dalam melakukan terminasi pada kasus kekerasan seksual anak adalah dengan meyakinkan keluarga korban maupun masyarakat dengan melibatkan perujuk, geuchik, pekerja sosial dan dinas terkait. Hambatan dan tantangan pekerja sosial Darussa'adah adalah ketika stakeholder klien sulit dimintai keterangan mengenai korban dan ada sebagian masyarakat yang menolak dan sebagian menerima korban. Adapun dukungan yang diterima pekerja sosial Darussa'adah adalah ketika perujuk bersedia kerjasama mencari cara agar mempermudah terminasi korban, dan juga keluarga serta masih ada masyarakat yang mau menerima di tengah-tengah sebagian besar masyarakat yang menolak korban kembali.

Kata Kunci: Kekerasan Seksual, Pendampingan Kasus, Terminasi. 


\section{Strategi dalam Melakukan Terminasi pada Kekerasan Seksual Anak di Lrsampk Darussa'adah}

- Rika Dewi Auliani Usman dan Nurul Husna

\section{Pendahuluan}

Pekerjaan sosial merupakan profesi yang bekerja sebagai pemecah masalah, baik itu masalah individu, keluarga, kelompok maupun masyarakat. Dalam menjalankan proses pertolongan, terdapat tahapan-tahapan yang dilakukan agar dalam menangani permasalahan sosial menjadi tepat sasaran. Proses yang dilakukan mulai dari engagement, intake, contract, assessment, planning, intervention, monitoring, evaluation, sampai dengan proses termination. Menurut Riem Malini Pane dalam Kottler, Sexton, \& Whitson (1994), terminasi adalah salah satu tahap dalam konseling di mana konselor harus mengakhiri konseling. Keputusan ini dapat dilakukan sepihak atau bersama. Terminasi menghasilkan perasaan campur aduk pada konselor, maupun klien. Terminasi mempunyai kekuatan melukai dan menyembuhkan

Terminasi merupakan aspek konseling yang paling sedikit dibahas. Karena terminasi mempunyai dampak pada semua pihak yang terlibat, dan biasanya kompleks dan rumit. Adapun tahapan dalam terminasi adalah memulai pengalaman baru, pengalaman sebelumnya harus dipecahkan dan diselesaikan, mempertahankan perubahan yang telah dicapai dan mengembangkan keahlian untuk memecahkan masalah yang telah diperoleh dari konseling, dan bertindak sebagai pengingat bahwa klien adalah orang dewasa (Hasna, Pekerja Sosial Darussa'adah, Juli 2019).

Kekerasan seksual adalah bentuk perilaku yang dilakukan seseorang atau sejumlah orang, tetapi tidak disukai oleh orang yang menjadi sasaran sehingga menimbulkan akibat negatif seperti rasa malu, tersinggung, terhina, marah, kehilangan harga diri, kehilangan kesucian, pada orang yang menjadi korban (Humaira, 2015). Beberapa dampak umum dari kekerasan terhadap anak dapat mengakibatkan berbagai gangguan mental saat dewasa, rentan terhadap depresi dan menunjukkan gejala-gejala traumatis hingga akhirnya beresiko tinggi menjadi pelaku kekerasan, dapat mengganggu proses tumbuh kembang anak, mengganggu perkembangan kecerdasan, dan bahkan berisiko menimbulkan masalah perilaku di masa depan.

Undang-Undang Perlindungan Anak Nomor 35 tahun 2014 (sebagai perubahan atas UU Perlindungan Anak Nomor 23 tahun 2002) pada pasal 9 menegaskan bahwa setiap anak berhak mendapatkan perlindungan di satuan pendidikan dari kejahatan seksual dan kekerasan yang dilakukan oleh pendidik, tenaga kependidikan, sesama peserta didik, dan/atau pihak lain (Kurniasari, 
2017). Data komnas perempuan menunjukkan pelaku tindakan kekerasan terbanyak adalah orang-orang terdekat korban seperti ayah, suami, paman, atau pacar korban, artinya kekerasan dalam rumah tangga (KDRT) merupakan tindak kekerasan yang paling banyak dilaporkan. Dari segi bentuk, kekerasan terhadap perempuan tidak hanya secara fisik, tetapi juga mengalami kekerasan psikis dan seksual (Subiyantoro, 2006).

\section{Metode}

Guna mendapatkan data secara mendalam dan terperinci, penelitian ini menggunakan metode penelitian kualitatif sebab dipandang lebih tepat digunakan untuk mendeskripsikan data-data yang diperlukan. Peneliti berusaha untuk memaparkan dan mendeskripsikan penelitian secara sistematis, faktual dan akurat mengenai fakta-fakta yang ditemukan di lapangan. Lokasi atau setting penelitian ini adalah Loka Rehabilitasi Sosial Anak Membutuhkan Perlindungan Khusus (LRSAMPK) Darussa'adah, Lampenerut Aceh Besar. Teknik penentuan informan menggunakan purposive sampling, yang menurut Sugiyono (2011) memberikan informasi secara tepat. Teknik yang digunakan di lapangan yaitu teknik observasi partisipasi moderat, teknik wawancara semi terstruktur, serta teknik dokumentasi menggunakan pedoman dokumenter berupa data-data peninggalan yang ada di tempat yang diteliti.

Teknik analisis data menggunakan beberapa tahapan yaitu mulai dengan mengorganisasikan data, menjabarkannya ke dalam unit-unit, melakukan sintesa, menyusun ke dalam pola, memilih mana yang penting dan yang akan dipelajari, dan membuat kesimpulan yang dapat diceritakan kepada orang lain.

\section{Hasil dan Diskusi}

Loka Rehabilitasi Sosial Anak Membutuhkan Perlindungan Khusus (LRSAMPK) Darussa'adah melakukan proses terminasi pada anak disesuaikan dengan kondisi anak dan keluarganya. Jika keluarga dan anak sudah siap maka LRSAMPKDarussa'adah bisa langsung melakukan terminasi. Tetapi SOP (Standar Operasional Prosedur) Darussa'adah menyebutkan bahwa proses terminasi bisa dilakukan apabila proses pendampingan atas korban sudah mencapai maksimal 6 (enam) bulan. Dengan waktu tersebut, baru dikatakan memenuhi kriteria untuk diterminasi. Tetapi hal ini pun harus dilakukan melalui pembahasan kasus terlebih dahulu. Jika memang selama 6 bulan belum siap dengan hasil 


\section{Strategi dalam Melakukan Terminasi pada Kekerasan Seksual Anak di Lrsampk Darussa'adah}

- Rika Dewi Auliani Usman dan Nurul Husna

case conference, berarti diperpanjang dan LRSAMPK Darussa'adah melakukan pendampingan lagi sampai keluarga, anak dan perujuk siap dilakukan proses terminasi.

Adapun lembaga yang menjadi perujuk LRSAMPK Darussa'adah adalah Dinas Sosial Provinsi, Dinas Sosial Kabupaten Kota, DP3A, dan P2TP2A. Dulu sebelum menjadi LRSAMPK Darussa'adah, lembaga pelayanan ini menerima korban dari masyarakat tetapi sekarang LRSAMPK Darussa'adah diarahkan untuk lokasi rujukan dari lembaga dan tidak menerima dari masyarakat ataupun media.

Pasca dilakukan terminasi, LRSAMPK melakukan pemantauan terhadap korban. Pemantauan tersebut bisa dilakukan dalam jangka waktu sebulan hingga tiga bulan. Kebanyakan dari korban kalau sudah dipulangkan, mereka tidak ada yang kembali lagi. Oleh sebab itu, pekerja Sosial LRSAMPK Darussa'adah sudah melakukan hal-hal yang dibutuhkan. Misalnya, jika ada sesuatu hal yang masih belum pas terhadap korban yang sudah diterminasi, pihak Pekerja Sosial LRSAMPK Darussa'adah segera meminta bantuan Sakti Peksos, kemudian ke P2TP2A, dan baru sampai Keuchik untuk memantau keadaan korban.

Strategi terminasi yang dilakukan oleh pekerja sosial LRSAMPK adalah dengan tetap mencari jalan untuk mengembalikan korban kepada orang tuanya atau keluarganya. Hambatan dan tantangan pekerja sosial ketika melakukan terminasi adalah ketika orang tua, lingkungan, pemerintahan setempat tidak menerimanya, atau bisa juga disebabkan oleh keputusan anaknya sendiri (korban) yang tidak mau pulang.

Pekerja sosial tidak bisa bekerja sendiri. Dengan kata lain, mereka membutuhkan dukungan terutama dari stakeholder dan perujuk. Dalam hal dukungan perujuk, ada beberapa kasus di mana perujuk begitu aktif dan hal ini sangat mendukung bagi pelayanan yang dilakukan pekerja sosial. Dengan dukungan aktif dari perujuk, ini tidak hanya dirasakan oleh LRSAMPK tetapi juga membantu memberi pemahaman kepada keluarga dan memudahkan dalam menangani dan mencari info dari korban. Sebaliknya, ada perujuk yang susah di mana mereka susah dihubungi kembali pasca merujuk. Dan ini menghambat proses kerja dari pekerja sosial.

Hal lain terkait hambatan yang dirasakan oleh pekerja sosial LRSAMPK Darussa'adah adalah menyangkut klien yang menjadi korban kekerasan seksual. Tak sedikit mereka (korban) diperlakukan sama seperti pelaku. Padahal anak 
di bawah usia 18 tahun tidak bisa dikenakan hukum. Meskipun anak tersebut bersalah, kesalahan anak itu mesti dipandang bahwa kesalahannya tidak hanya terdapat dari si anaknya saja, namun bisa dari pengaruh pengasuhan orang tuanya, dan lingkungannya yang tidak baik.

Agus salah seorang pekerja sosial (2019) mengatakan bahwa apabila korban kekerasan seksual hamil, maka keluarga klien akan diterminasi, dan tetap akan diupayakan bayinya dengan keluarga. Tetapi jika keluarga tidak layak untuk mengasuh si bayi maka LRSAMPK Darussa'adah melakukan COTA (calon orang tua asuh). Tindakan COTA diambil sebagai jalan terakhir apabila pihak keluarga tidak mau menerima si bayi. Selain itu, menurut Agung (2019), apabila keluarga susah dihubungi, maka jalan komunikasi para pekerja sosial dilakukan dengan menghubungi Keuchik, Dinas Sosial dan instansi lain seperti Sakti Peksos dan TKSK.

Adapun terkait status ekonomi korban, rata-rata mereka adalah kelas menengah ke bawah, dan juga status pengasuhannya rata-rata dari keluarga broken home, dan ada juga yang dirawat oleh neneknya. Ketika korban sudah habis masa pelayanannya, mereka tetap diupayakan dikembalikan kepada keluarganya, dan tetap dicarikan jalan keluar agar masyarakat mau menerima korban. Sehingga tidak harus di rujuk ke lembaga lain.

Kontrak awal terminasi sangat berpengaruh, terutama dengan perujuk. Jika tidak ada kontrak dari awal, maka mereka lepas tangan. Sehingga sejak dari awal harus ada janji, misalnya dari LRSAMPK Darussa'adah menangani kendala apa, dan dari perujuk menangani kendala apa. Adapun mengenai proses rujukan ke lembaga lain ketika Darussa'adah tidak mampu menangani korban dilakukan dengan mula-mula Pekerja Sosial LRSAMPK Darussa'adah menjalin silaturahmi lembaga rujukan. Di sana pekerja sosial LRSAMPK bertanya apakah lembaga yang dirujuk bersedia tidak dengan permasalahan yang ada, jika bersedia buat kesepakatan dulu, dari mereka mau menerima, pihak Darussa'adah mengambil bagian apa yang belum ada.

Fakhrul Razi Anwir dari Dinas Pemberdayaan Perempuan dan Perlindungan Anak (DP3A) Aceh mengatakan kasus kekerasan pada perempuan dan anak di Aceh, cenderung meningkat dalam tiga tahun terakhir (2018). Menurut data yang dicatat pihaknya, pada tahun 2015 di Aceh tercatat sebanyak 939 kasus, tahun 2016 ada sebanyak 1.648 kasus, dan tahun 2017 kembali meningkat sebanyak 1.791 kasus. Dari keseluruhan kasus kekerasan pada tahun 
2017 tersebut, kasus kekerasan psikis mendominasi kasus kekerasan terhadap perempuan sebanyak 359 kasus, kekerasan dalam rumah tangga (KDRT) 316 kasus, dan kekerasan fisik 255 kasus. Kemudian kasus kekerasan yang menimpa anak yang disebabkan oleh kekerasan psikis berjumlah 399 kasus, kekerasan fisik 165 kasus, dan pelecehan seksual 240 kasus.

Sedangkan di Loka Rehabilitasi Sosial Anak Membutuhkan Perlindungan Khusus (LRSAMPK) Darussa'adah Aceh Besar sudah terdata jumlah korban pada tahun 2015 berjumlah 40 orang, pada tahun 2016 berjumlah 47 orang, pada tahun 2017 berjumlah 18 orang. Di mana dari data korban tersebut, yang dominan adalah mereka menjadi korban incest.

\section{Kesimpulan}

Jenis kasus kekerasan seksual anak yang ditangani oleh pendamping LRSAMPK Darussa'adah adalah perkosaan, pelecehan seksual, eksploitasi seksual, kekerasan dalam keluarga, penelentaran bayi, perdagangan atau penculikan untuk tujuan seksual. Kekerasan seksual yang terjadi pada anak juga dilakukan oleh orang terdekat korban seperti ayah, abang, paman, pacar, dan tetangga korban.

Strategi yang dilakukan pekerja sosial LRSAMPK Darussa'adah ketika terminasi atau pemutusan layanan dengan klien adalah meyakinkan keluarga korban dan masyarakat bahwa korban butuh dampingan, butuh pengobatan baik fisik maupun psikis, butuh kasih sayang, dan juga dukungan dari keluarga maupun masyarakat sekitar. Dan ketika klien tetap tidak diterima, pekerja sosial mencari cara lain, dengan cara melibatkan perujuk, keluarga, geuchik, dan dinas terkait, untuk dapat menceritakan betapa sulitnya korban kekerasan seksual sehingga harus menanggung beban diri sendiri dan juga menanggung beban dari perbuatan keji orang terhadap dirinya.

\section{Daftar Pustaka}

Kurniasari, A. (2017). Dampak Kekerasan pada Kepribadian Anak (Impact of Violence in Children's Personality). Jakarta Timur. Diakses dari https://ejournal.kemsos.go.id/index.php/Sosioinforma/article/view/1594/936

Humaira, D., dkk. (2015). Kekerasan Seksual pada Anak: Telaah Relasi Pelaku Korban dan Kerentanan Pada Anak. Psikoislamika: Jurnal Psikologi dan Psikologi Islam. Volume 12. DOI: 10.18860/psi.v12i2.6398. 
Subiyantoro, E.B. (2006). Advokasi Anti Kekerasan terhadap Perempuan: Pengalaman Forum Belajar Bersama Komnas Perempuan. Cetakan pertama. Jakarta: Komnas Perempuan.

Anwir, F.R. Kasus Kekerasan Terhadap Perempuan dan Anak Meningkat di Aceh. Aceh Journal National Network, 4 Mei 2018. Diakses dari http://www.ajnn. net/news/kasus-kekerasan-terhadap-perempuan-dan-anak-meningkat-di-aceh/index.html)

Amalia, I. (2015). Pendampingan Anak Korban Kekerasan Fisik di Lembaga Perlindungan Anak (LPA) Yogyakarta. Skripsi UIN Sunan Kalijaga Yogyakarta.

Sugiyono, (2011). Metode Penelitian Kuantitatif, Kualitatif dan R\&D. Bandung: Penerbit Alfabeta, 2011. 